University of Nebraska - Lincoln

DigitalCommons@University of Nebraska - Lincoln

4-1-2002

\title{
Pore structure, barrier layer topography and matrix alumina structure of porous anodic alumina film
}

\author{
Yucheng Sui \\ University of Nebraska-Lincoln, ysui2@unl.edu \\ B.Z. Cui \\ Kansas State University, Manhattan, KS \\ L. Martinez \\ Centro de Ciencias Físicas, Cuernavaca, Morelos, Mexico \\ R. Perez \\ Instituto Mexicano del Petróleo. Eje Central Lázaro Cárdenas, Mexico \\ David J. Sellmyer \\ University of Nebraska-Lincoln, dsellmyer@unl.edu
}

Follow this and additional works at: https://digitalcommons.unl.edu/physicssellmyer

Part of the Physics Commons

Sui, Yucheng; Cui, B.Z.; Martinez, L.; Perez, R.; and Sellmyer, David J., "Pore structure, barrier layer topography and matrix alumina structure of porous anodic alumina film" (2002). David Sellmyer Publications. 197.

https://digitalcommons.unl.edu/physicssellmyer/197

This Article is brought to you for free and open access by the Research Papers in Physics and Astronomy at DigitalCommons@University of Nebraska - Lincoln. It has been accepted for inclusion in David Sellmyer Publications by an authorized administrator of DigitalCommons@University of Nebraska - Lincoln. 
Published in Thin Solid Films 406:1-2 (March 1, 2002), pp. 64-69. Copyright (C) 2002 Elsevier Science B.V. Used by permission.

doi:10.1016/S0040-6090(01)01769-2 http://www.sciencedirect.com/science/journal/00406090

\title{
Pore structure, barrier layer topography and matrix alumina structure of porous anodic alumina film
}

\author{
Y. C. Sui ${ }^{\text {a, b,* }}$, B. Z. Cuic, L. Martínez ${ }^{\text {d }}$ R. Perez ${ }^{\text {b }}$ and D. J. Sellmyer ${ }^{\mathrm{a}}$ \\ ${ }^{a}$ Department of Physics and Astronomy and Center for Materials Research and Analysis, University of Nebraska-Lincoln, 116 Brace Lab, \\ P.O. Box 880111, Nebraska, NE, 68588-0111, USA \\ b Instituto Mexicano del Petróleo. Eje Central Lázaro Cárdenas No. 152, C.P. 07730, Mexico, D. F., Mexico

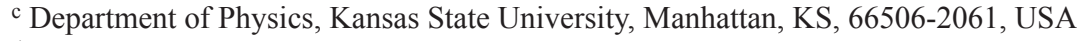 \\ ${ }^{\mathrm{d}}$ Centro de Ciencias Físicas, UNAM, A. P. 48-3, C.P. 62251, Cuernavaca, Morelos, Mexico \\ * Corresponding author. Tel.: email: yunchengsui@yahoo.com
}

Submitted January 2001; revised September 2001; accepted December 11, 2001; available online January 15, 2002.

\begin{abstract}
Different anodic voltages and methods were adopted to produce porous anodic alumina films (PAAF) in an aqueous solution of oxalic acid. Carbon tube growth by chemical vapor deposition (CVD) in the films was used to copy the internal pore structure and was recorded by transmission electron microscopy (TEM) photos. Atomic force microscope (AFM) was employed to obtain the topography of the barrier layer of the corresponding films. When the anodic voltage was $40 \mathrm{~V}$ and the two-step method adopted, the barrier layer of the film had domains with highly ordered hexagonal cell distribution, and the corresponding pores were straight. When the anodic voltage increased to $60 \mathrm{~V}$, the barrier layer showed random cell distribution with an obvious difference in cell size and form, and the corresponding pores exhibited multi-branch features. When the anodic voltage increased further to $110 \mathrm{~V}$, the barrier layer also showed a random cell distribution. Additionally, smaller protrusions connected to bigger cells were found, which can be correlated to the formation of branches with smaller diameters. Most of the branches of carbon tubes grown in the film anodized at $110 \mathrm{~V}$ have a saw-tooth like feature. X-Ray diffraction analysis shows that all the anodic films are amorphous, regardless of the anodic voltage. However, unoxidized aluminum particles in the film anodized at 110 $\mathrm{V}$ was observed by TEM.
\end{abstract}

Author Keywords: Anodic oxidation, Carbon, Chemical vapor deposition, Nanostructures, TEM, AFM

\section{Introduction}

Porous anodic alumina films have received great attention, due to their utilization as templates for device fabrications on a nanometer scale $[1,2,3$, 4 and 5]. The structure of porous anodic alumina is described as a close-packed hexagonal array of columnar cells, each containing a central pore, of which the size and interval can be controlled by changing the forming conditions [6]. The striking feature of this film is the extremely high aspect ratio of their nanochannels, which is difficult to achieve with conventional lithographic techniques. Self-organized hexagonal pore arrays can be formed naturally in sulfuric, oxalic and phosphoric acid solutions under appropriate anodic voltage [7, 8 and 9].

The porous structure evolution results from the dynamic equilibrium between the film growth at the aluminum-alumina interface and the field-assisted oxide dissolution at the oxide-electrolyte interface [10]. Both $\mathrm{Al}^{3+}$ and $\mathrm{O}^{2-}$ passed through the barrier layer under the driving force of the electric field. Therefore, the study of the barrier layer structure might yield direct information on the dynamic evolution of pore growth.

As a template, the internal pore structure of PAAF will have an inevitable influence on their applications. It was reported that carbon nanotubes grown in PAAF can copy the internal pore structure [11 and 12], so in this study, CVD carbon tube growth in pores was used to record the internal pore structure. Attempts were made to correlate the pore structures, barrier layer topographies and the alumina matrix examined by X-ray and TEM. 


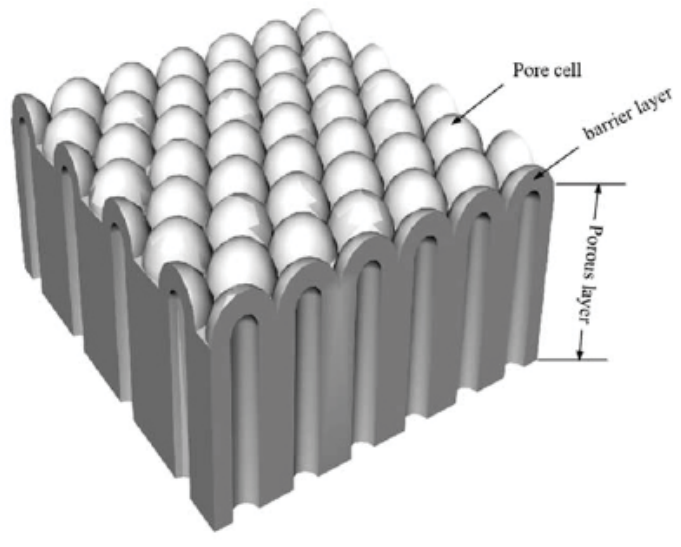

Fig. 1. Illustration of an ideal structure of self-organized growth of PAAF.

\section{Experimental methods}

Pure Al (99.999\%) plates were annealed at 500 ${ }^{\circ} \mathrm{C}$ and electrochemically polished in $(5: 1 \mathrm{v} / \mathrm{v}$ solution of $\mathrm{EtOH} / \mathrm{HClO}_{4}$ ) for approximately $3 \mathrm{~min}$ at $20 \mathrm{~V}$. The polished aluminum plates were anodized at $15{ }^{\circ} \mathrm{C}$ under different anodic voltage in $0.16 \mathrm{M}$ aqueous solution of oxalic acid for $25 \mathrm{~min}$, with the graphite plate as counter-electrode.

After anodization, the remaining aluminum was removed in a saturated $\mathrm{HgCl}_{2}$ solution and cleaned thoroughly using distilled water in order to get clean PAAF. For carbon tube growth, the stripped and cleaned films were placed in a tubular furnace with a flow of gas mixture of $\mathrm{N}_{2}(90 \%)$ and $\mathrm{C}_{2} \mathrm{H}_{2}(10 \%)$, at a rate of $100 \mathrm{ml} / \mathrm{min}$ at $650{ }^{\circ} \mathrm{C}$ for $2 \mathrm{~h}$. Then, the tube containing films was cooled to room temperature and the tubes were released in a $15 \% \mathrm{NaOH}$ solution. The washed and dried tubes were dispersed in pure $\mathrm{EtOH}$ by sonication. A drop of suspension of the nanotubes was placed on a TEM (JEOL 2000EX) grid for structure observation. The topography of the barrier layer was obtained on films using AFM (Auto Probe CP, Park Company) under contact mode. The adopted Ultralever ${ }^{\mathrm{TM}}\left(\mathrm{Si}_{3} \mathrm{~N}_{4}\right.$ tip) has an average force constant of $0.4 \mathrm{~N} / \mathrm{m}$. X-Ray diffractograms were obtained using a Siemens D-5000 diffractometer with $\mathrm{Cu} \mathrm{K} \alpha$ radiation at $35 \mathrm{KV}, 30 \mathrm{Ma}$, a step size of $0.04^{\circ}$ and during $20 \mathrm{~s}$. The stripped and cleaned anodic films were pulverized to powder and dispersed in pure EtOH by sonication. A drop of suspension of the film powder was placed on a grid for TEM (JEOL 2000EX) structure examination. (a)

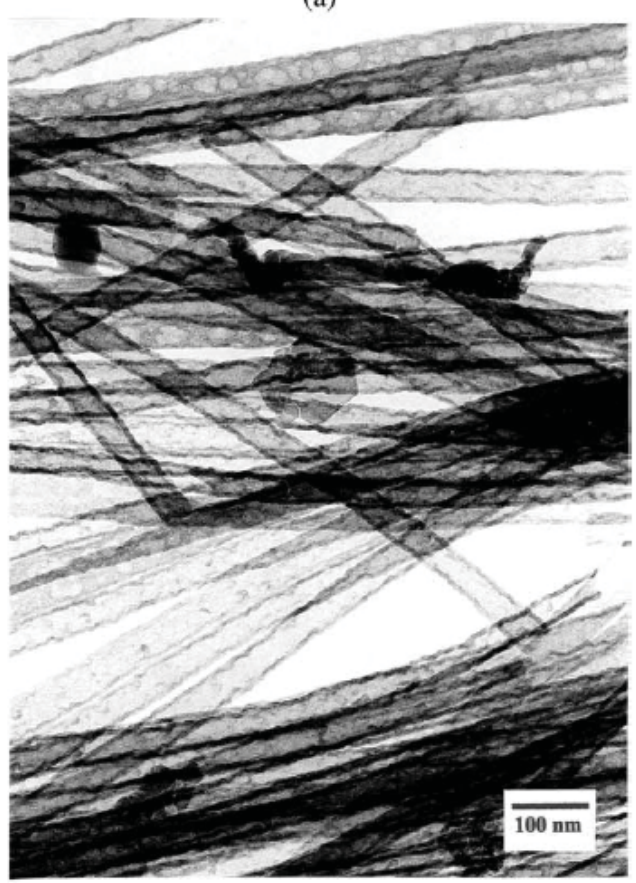

(b)

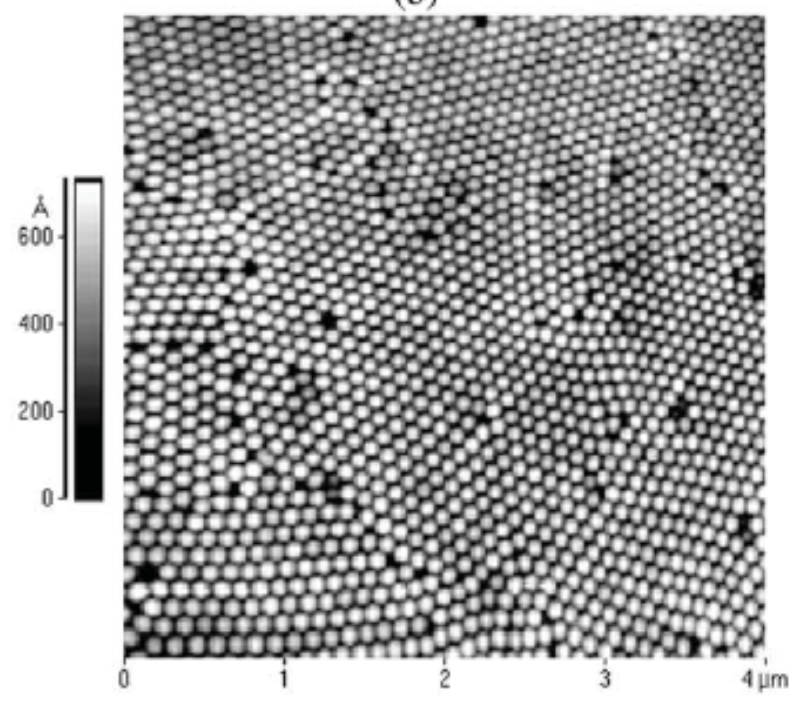

Fig. 2. TEM images of carbon tubes grown in PAAF using the two-step method (a) and AFM topography of the barrier layer of the corresponding PAAF (b).

\section{Results and discussions}

\subsection{PAAF with straight pore structure}

Fig. 1 shows an illustration of the ideal structure of self-organized growth of PAAF. The barrier layer consists of a regular hexagonal array of hemispherical cells having a pore beneath each one, which is a generally accepted prototype of PAAF. 
The two-step method used for preparing alumina films was reported in detail elsewhere [13 and 14]. Fig. 2a shows the TEM images of carbon tubes grown in film using the two-step method. The anodic voltage is $40 \mathrm{~V}$ and the second-step oxidation time is $25 \mathrm{~min}$. It is found that all the tubes are straight, with a narrow diameter distribution ranging from 37 to $50 \mathrm{~nm}$, which indicates a narrow diameter distribution of the pores in the film. Also, it is found that the tubes have a relatively rough surface feature. When the films were corroded in $0.1 \mathrm{M} \mathrm{H}_{3} \mathrm{PO}_{4}$ solution at $35{ }^{\circ} \mathrm{C}$ for $20 \mathrm{~min}$, the resulting carbon tubes have smooth surfaces at the expense of larger tube diameters. This phenomenon indicates that the rough tube surfaces were not caused by the film variation at higher temperatures during the CVD tube growth. It is the true reflection of the pore internal surface without corroding in $\mathrm{H}_{3} \mathrm{PO}_{4}$ solution. Film corrosion in $\mathrm{H}_{3} \mathrm{PO}_{4}$ solution can smooth the pore internal surfaces at the expense of a larger diameter.

Fig. 2b shows the AFM topography of the barrier layer of the corresponding PAAF, which contains domains with highly regular hexagonal cell distribution, some defects (holes) exist at the boundary of the domains, which might be caused by metallurgical defects. Because all the tubes are straight, under TEM observation, one might conclude that the existence of some defects in alumina film does not affect the straight pore growth and structure. In other words, perfect hexagonal cell distribution in the barrier layer is not the only case where straight pore structure can be formed.

Due to different thermal expansion coefficients between alumina and aluminum substrate, pore cracking was claimed to occur during heating and cooling [15], which will certainly affect the form of carbon tubes grown in the pores. Extensive TEM observations show that carbon tubes grown in PAAF with aluminum substrate have the same round feature as that in PAAF without aluminum substrate. This result might indicate that the cracking of the films on the aluminum substrate occurred through the cell boundaries and did not pass through the pores [16], so the obtained tubes remained round, rather than another complex shape, if the crack occurred through the pores. The reported study was carried out on film anodized in sulfuric acid solution and the fracture was realized by $180^{\circ}$ sharp bending [16]. In our case, the film was obtained by anodizing in oxalic acid solu-

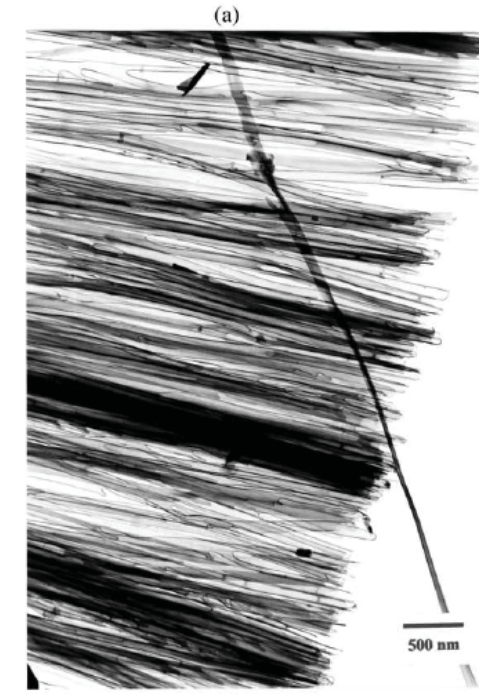

(b)

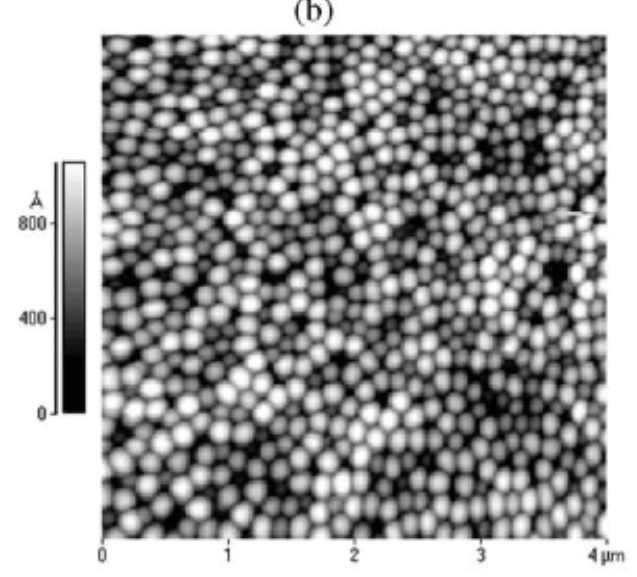

Fig. 3. TEM images of carbon tubes grown in PAAF anodized at $60 \mathrm{~V}$ (a) and the corresponding AFM topography of the barrier layer (b).

tion and the fracture was induced by heat expansion, but it may also occur through the cell boundaries.

\subsection{PAAF with branched pore structure}

Fig. 3a,b shows, respectively, the structure of carbon tubes grown in PAAF anodized at $60 \mathrm{~V}$ and the corresponding barrier layer topography, respectively. It can be found that the tubes exhibit a multi-branched structure, which indicates multi-branched internal pore structure in PAAF. Contrary to the rough surface features and smaller diameter of tubes grown in film anodized at $40 \mathrm{~V}$, the tubes grown in films anodized at $60 \mathrm{~V}$ have a larger diameter and smooth surface (except the branch junctions), suggesting that the multi-branched pores or pores formed at higher anodic voltage have a smooth internal surface.

The AFM topography of the barrier layer of film anodized at $60 \mathrm{~V}$ also differs greatly from that anod- 


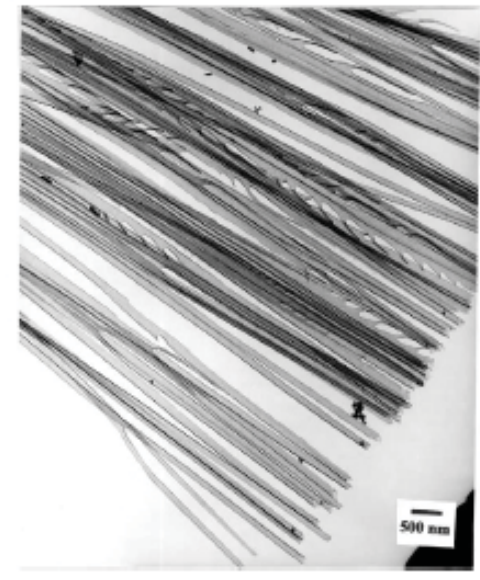

Fig. 4. TEM image of carbon tubes grown in PAAF anodized at $110 \mathrm{~V}$.

ized at $40 \mathrm{~V}$ by the two-step method. The cells exhibit an irregular and distorted distribution, the sizes of the cells range from 100 to $250 \mathrm{~nm}$. The analysis of cell features reveals interesting information. Some cells appear as an elongated island, which may be related with the nucleation of a branching pore. The holes in the barrier layer may be related with the termination of a pore growth, which will be closed due to the possible reorientation of cell growth or possible nucleation of a new branch in the surrounding cell growth. Combining the three-dimensional pore structure with the topography of barrier layer, it can be known that the topography of barrier layer is a direct manifestation of internal pore structure.

In order to test the effect of the higher anodic voltage on the feature of pore structure, another film was prepared by anodizing at constant voltage of $110 \mathrm{~V}$. Subsequent characterizations of pore structure and barrier layer were carried out as before. Fig. 4 shows the structure of carbon tubes grown in the film anodized at $110 \mathrm{~V}$. Although the anodic voltage for film growth was increased greatly, the number of the branches does not show observable increase, compared with that anodized at $60 \mathrm{~V}$. Most of the branches have much smaller diameters than the main tubes and exhibit saw-like features, which suggest that most of the branched internal pores have branches with smaller diameters situated like saws. After extensive TEM observation, it was found that there also exists a small amount of symmetrical branches, as shown in the bottom of Fig. 4, the two symmetrical branches have a similar diameter.

Fig. 5a,b shows two typical topographies observed on the barrier layer of film obtained at $110 \mathrm{~V}$. A large amount of bigger cells associated with smaller ones were observed in Fig. 5a. On the contrary, no smaller cells can be found in Fig. 5b, the general feature of Fig. $5 \mathrm{~b}$ is similar to that in Fig. 3b.Comparing the topography of the barrier layer with the corresponding branched structure of the carbon tubes, it seems reasonable that the smaller protrusions associated with the bigger cells can be correlated with the smaller pore branch, situated on one side of the main pore. Now that the pores are formed by field-assisted oxide dissolution at the oxide-electrolyte interface, the smaller lengths and diameters of the branches than the main tubes might imply a relatively inhibited dissolution of alumina in the branch-site than in the main pore-site. The poor orientation of the branches with the external electric field may slow down the diffusion of $\mathrm{Al}^{3+}$ and $\mathrm{O}^{2-}$ through the barrier layer, as both of them are field-assisted process. So less dissolution of alumina maybe expected. The equilibrium between the alumina dissolution and film growth was broken at the end of the branch, and consequently, the growth of the branching pores ceased. As pore growth is a dynamic process, many parameters may
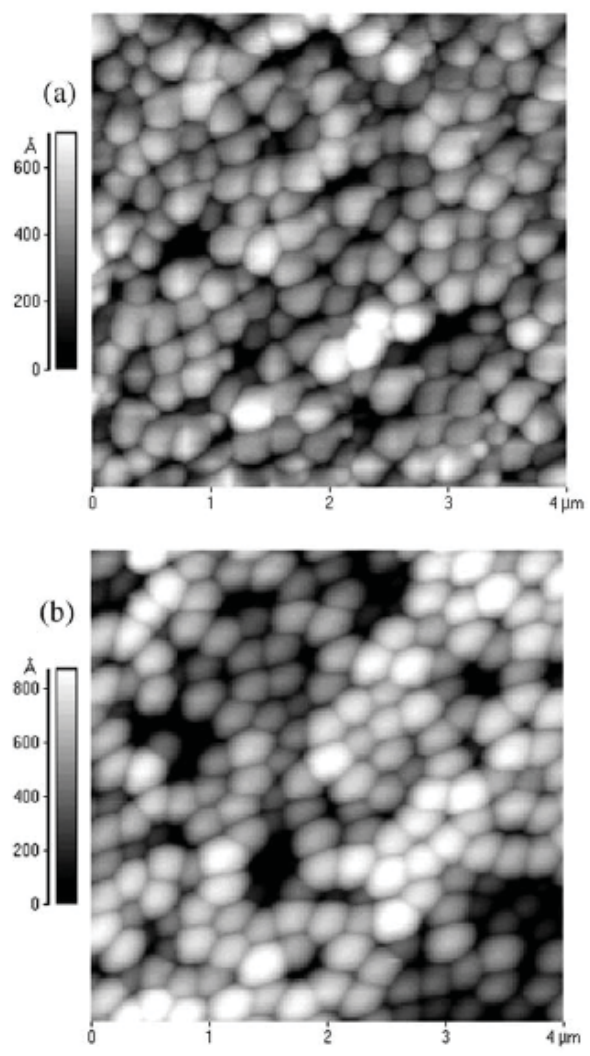

Fig. 5. Two typical topographies observed on the barrier layer of PAAF obtained at $110 \mathrm{~V}$, indicated as (a) and (b). 


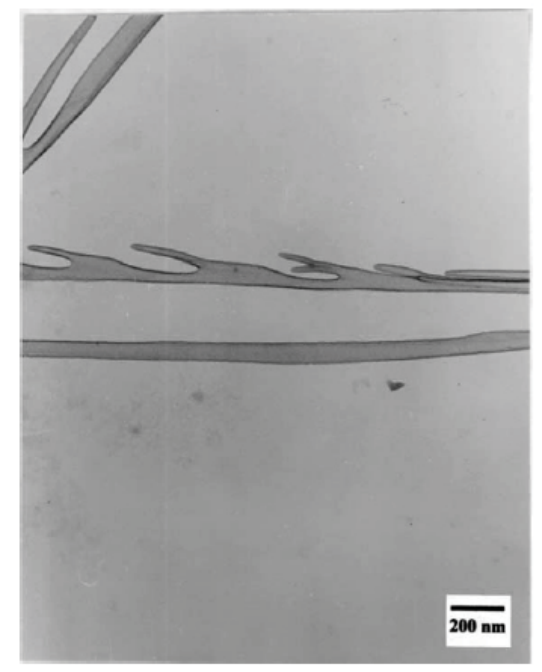

Fig. 6. TEM image of carbon tubes with secondary branches grown in PAAF anodized in $0.3 \mathrm{M}$ oxalic solution at $60 \mathrm{~V}$.

affect its structure, including metallurgical defects, growing temperature, the growth of its neighboring pores, etc. Further work is needed to clarify the mechanism of the formation of smaller and saw-like branches at $110 \mathrm{~V}$.

\subsection{PAAF with secondary branches}

With the help of CVD carbon tube growth in anodic films and subsequent TEM observation, one can get a clear three-dimension image of pore structure in the films. When the films were made by anodizing in $0.16 \mathrm{M}$ oxalic acid solution at $15^{\circ} \mathrm{C}$ using constant anodic voltages, no secondary branches were observed, i.e. all the observed branches did not show further ramification, regardless of the anodic voltage (from 60 to $110 \mathrm{~V}$ ). Also, we have not found two branches nucleated at the same site.

Fig. 6 shows one TEM image of carbon tubes grown in film anodized in $0.3 \mathrm{M}$ oxalic solution at $15^{\circ} \mathrm{C}$, the anodic voltage is $60 \mathrm{~V}$. It can be found that secondary branches were formed at the end of one branch. Next to this site, two branches (one is bigger and the other smaller) are almost nucleated at the same position. Although these two features are not common in this kind of sample, one may conclude that the formation of new secondary branches and nucleation of two branches at almost the same place is possible. The topography of the barrier layer does not show observable difference for the adoption of either a 0.3 or $0.16 \mathrm{M}$ solution. So the pore structures in anodic films are very complex, depending mainly on the experimental parameters. The irregular and distorted cell distributions may imply the existence of both first and second branches.

It was demonstrated that both cell diameter and pore diameter are directly proportional to the formation voltage [6]. In this experiment, pore diameter measured from carbon tubes and cell size measured on barrier layer by AFM, can be correlated to each other approximately. In this sense, PAAF characterization by topography on barrier layer is a convincing and convenient way.

\subsection{Structure of PAAF by X-ray diffraction analysis and TEM}

It is widely accepted that PAAF is of amorphous or nanostructure nature, with a mean crystallite size less than $4 \mathrm{~nm}$ [17 and 18]. In order to find the possible relationship between the pore structure and the alumina matrix, both X-ray diffraction and TEM were employed to get additional matrix information. Fig. 7 shows the X-ray diffraction patterns of the film anodized at 40, 60 and $110 \mathrm{~V}$. It was found that all the films are amorphous, regardless of the anodic voltage, or in other words, regardless of the internal pore structures.

TEM observations show that the anodic films obtained at 40 or $60 \mathrm{~V}$ consist only of amorphous alumina, but the film obtained at $110 \mathrm{~V}$ consists of an amorphous alumina matrix, with a smaller number of unoxidized aluminum particles. Fig. 8 shows the

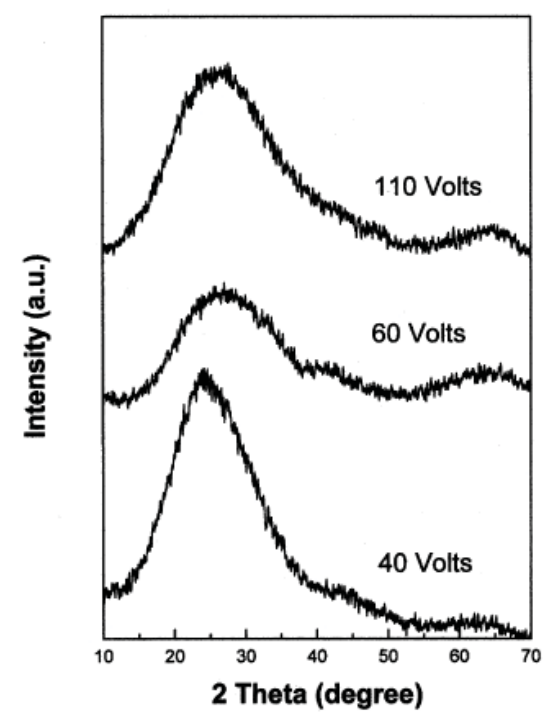

Fig. 7. X-Ray diffraction patterns of PAAF anodized at 40, 60 and $110 \mathrm{~V}$, respectively. 


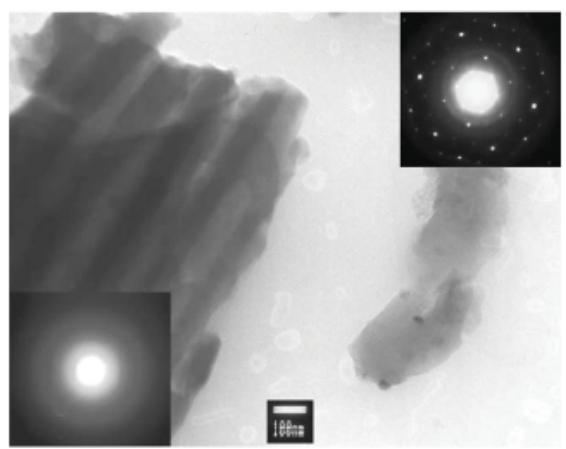

Fig. 8. TEM image of PAAF anodized at $110 \mathrm{~V}$ with unoxidized aluminum particles. Insets show the electron diffraction pattern of alumina matrix (left lower corner) and aluminum particles (right upper corner).

TEM image of alumina anodized at $110 \mathrm{~V}$, the particle sizes of unoxidized aluminum particles range from 10 to $40 \mathrm{~nm}$. When the films were anodized in sulfuric acid solution, unoxidized aluminum particles were found by the measurement of the optical transmission loss [19]. Our TEM experiment gives a direct observation of unoxidized aluminum particles in PAAF anodized in oxalic acid solution.

During TEM observation, it was found that the small unoxidized aluminum particle disappeared quickly with the activation of electron beam attack and did not permit further analysis, which indicates that very smaller particles are not stable in the amorphous alumina matrix. Although no unoxidized aluminum particles were observed in PAAF anodized at 60 and $40 \mathrm{~V}$, tiny unoxidized aluminum particles may also exist in them and TEM was unable to find and record them due to their instability.

\section{Conclusions}

The internal pore structure of PAAF formed at constant anodic voltage is complex, being straight with a relatively rough surface or multi branched with a smooth surface. The average diameters of branches are smaller at $110 \mathrm{~V}$ than that obtained at $60 \mathrm{~V}$, when the anodic voltage remained constant and the electrolyte was changed to $0.3 \mathrm{M}$, secondary branches were obtained. The cell shape and distribution in the barrier layer can be directly related to the internal pore structure, which exhibits a dynamic process of branch nucleation and termination. Ordered hexagonal cell distribution implies a film comprised of uniform columnar array of parallelsided, closely packed hexagonal alumina cells, with a straight pore in the center of each cell, while dif- ferent cell sizes, shapes and random distribution of cells mean multi branched internal pore structure.

When the anodic voltage is higher, larger cell size and bigger pore diameters were obtained. In this sense, the topography of barrier layer gives not only the information of pore ramification, but also the information of pore sizes underneath the cells. $\mathrm{X}$-Ray diffraction analysis shows that all the AAO films are amorphous regardless of the anodic voltage. TEM examinations show that there exist unoxidized aluminum particles in the anodized film.

\section{Acknowledgements}

The authors are very grateful for X-ray analysis by Leticia Baños in Instituto de Investigacion en Materials of UNAM. We would like to acknowledge R. Guardián and E. Ovalle-Garcia for his technical support of Centro de Ciencia Fisica of UNAM. Research at the University of Nebraska was supported by NSF, ARO, NRI and CMRA.

\section{References}

1. D.J. Sellmyer, M. Zheng and R. Skomski J. Phys. Condens. Matter 13 (2001), p. R433.

2. D. Routkevitch, A.A. Tager, J. Haruyama, D. Almawlawi, M. Moskovits and J.M. Xu IEEE Trans. Eletron Devices 43 (1996), p. 1646.

3. N. Kouklin, S. Bandyopadhyay, S. Tereshin, A. Varfolomeev and D. Zaretsky Appl. Phys. Lett. 76 (2000), p. 460.

4. P.R. Evans, G. Yi and W. Schwarzacher Appl. Phys. Lett. 76 (2000), p. 481.

5. P. Katiyar, D. Kumar, T.K. Nath, A.V. Kvit, J. Narayan, S. Chattopadhyay, W.M. Gilmore, S. Coleman, C.B. Lee, J. Sankar and R.K. Singh Appl. Phys. Lett. 79 (2001), p. 1328.

6. J.P. O'Sullivan and G.C. Wood Proc. R. Soc. Lond., Ser. A 317 (1970), p. 511.

7. A.P. Li, F. Müller, A. Birner, K. Nielsch and U. Gösele J. Appl. Phys. 84 (1998), p. 6023.

8. H. Masuda and K. Fukuda Science 268 (1995), p. 1466.

9. H. Masuda, F. Hasegawa and S. Ono J. Electrochem. Soc. 144 (1997), p. L127.

10. G. Patermarakis, P. Lenas, C. Karavassilis and G. Papayiannis Electrochim. Acta 36 (1991), p. 709.

11. Y.C. Sui, J.A. González-león, A. Bermúdez and J.M. Saniger Carbon 39 (2001), p. 1709.

12. Y.C. Sui, D.R. Acosta, J.A. González-león, A. Bermúdez, J. Feuchtwanger, B.Z. Cui, J.O. Flores and J.M. Saniger J. Phys. Chem. B 105 (2001), p. 1523.

13. H. Masuda and M. Satoh Jpn. J. Appl. Phys. Part 235 (1996), p. L126.

14. Y.C. Sui and J.M. Saniger Mater. Lett. 48 (2001), p. 127.

15. T. Iwasaki, T. Motoi and T. Den Appl. Phys. Lett. 75 (1999), p. 2044.

16. D.J. Arrowsmith, A.W. Clifford and D.A. Moth J. Mater. Sci. Lett. 5 (1986), p. 921.

17. G.E. Thompson, R.C. Furneaux and G.C. Wood Corros. Sci. 18 (1978), p. 481.

18. B. Baker and R. Pearson J. Electrochem. Soc. 119 (1972), p. 160.

19. M. Saito, Y. Shiga and M. Miyagi J. Electrochem. Soc. 140 (1993), p. 1907. 